\title{
Food Insecurity Experience: Building Empathy in Future Food and Nutrition Professionals
}

\section{Authors: Alison H. Harmon, Kara Landolfi, Carmen Byker Shanks, Leanna Hansen, Laura Iverson, and Melody Anacker}

NOTICE: this is the author's version of a work that was accepted for publication in Journal of Nutrition Education and Behavior. Changes resulting from the publishing process, such as peer review, editing, corrections, structural formatting, and other quality control mechanisms may not be reflected in this document. Changes may have been made to this work since it was submitted for publication. A definitive version was subsequently published in Journal of Nutrition Education and Behavior, VOL\# 49, ISSUE\# 3, (March 2017)] DOI\# 10.1016/j.jneb.2016.10.023

Harmon, Alison, Kara Landolfi, Carmen Byker Shanks, Leanna Hansen, Laura Iverson, and Melody Anacker. "Food Insecurity Experience: Building Empathy in Future Food and Nutrition Professionals." Journal of Nutrition Education and Behavior (March 2017).

DOI: 10.1016/j.jneb.2016.10.023.

Made available through Montana State University's $\underline{\text { ScholarWorks }}$ scholarworks. montana.edu 


\title{
Food Insecurity Experience: Building Empathy in Future Food and Nutrition Professionals
}

\author{
Alison Harmon, PhD, RD, LN ${ }^{1}$; Kara Landolfi, MS ${ }^{1}$; Carmen Byker Shanks, PhD, RD ${ }^{1}$; \\ Leanna Hansen, $\mathrm{BS}^{2}$; Laura Iverson, MS, RD ${ }^{3}$; Melody Anacker, MS, RD ${ }^{1}$
}

\begin{abstract}
Objective: To assess changes in empathy in students completing a food insecurity experience.

Design: Mixed methods; quantitative data from survey in years 1 and 2; qualitative data extracted from students' workbooks in years $2-5$. This study was conducted over 10 weeks annually for 5 years.

Setting: Northwest US land-grant university.

Participants: Students enrolled in a community nutrition course who chose to complete the food insecurity exercise. Total included 58 students in quantitative analysis in years 1 and 2 and 119 in qualitative analysis, years 2-5.

Intervention(s): The intervention was a food insecurity experience in which participants spent no more than $\$ 3 /$ d on food for 5 days ( $\$ 15$ total) while striving for a nutritious diet and reflecting on their experience.

Main Outcome Measures: Empathy scores measured by Likert scales; participant responses and reflections recorded in workbook journals.

Analysis: Comparison of means across time using paired $t$ tests $(P<.05)$; coding and sorting themes from workbook journals.

Results: Quantitative findings indicated that both classroom content and experiential exercises were important for enhancing empathy about food insecurity. Empathy scores increased from time I to time II and from time I to time III. Qualitative reflections among participants included terms such as guilt, empathy, compassion, and raised consciousness about food insecurity.

Conclusions and Implications: Experiential and transformational learning to develop empathy can take place in a 5-day food insecurity experience during a typical university-level community nutrition course. This intervention can be tested for applications in other contexts.

Key Words: community nutrition students, food insecurity, dietetics education, food assistance, transformational learning theory (J Nutr Educ Behav. 2017;49:218-227.)
\end{abstract}

Accepted October 26, 2016. Published online December 18, 2016.

\section{INTRODUCTION}

Food security is defined as having "consistent, dependable access to enough food for active, healthy living." ${ }^{1}$ Approximately $12.7 \%$ of households (42.2 million individuals) in the US

\footnotetext{
${ }^{1}$ Department of Health and Human Development, Montana State University, Bozeman, MT

${ }^{2}$ Wisconsin School of Medicine, Milwaukee, WI

${ }^{3}$ St. James Healthcare, Butte, MT

Conflict of Interest Disclosure: The authors' conflict of interest disclosures can be found online with this article on www.jneb.org.

Address for correspondence: Alison Harmon, PhD, RD, LN, Department of Health and Human Development, College of Education, Health, and Development, Montana State University, 250 Reid Hall, Bozeman, MT 59717; Phone: (406) 994-6338 Fax: (406) 9941854; E-mail: harmon@montana.edu

(C2016 Society for Nutrition Education and Behavior. Published by Elsevier, Inc. All rights reserved.

http://dx.doi.org/10.1016/j.jneb.2016.10.023
}

and lowers academic achievement; and it is implicated in chronic disease and mental disorders, and has a paradoxical relationship with body mass index. ${ }^{3-17}$

It is difficult to afford nutritious foods on a limited budget, which exacerbates chronic disease risk for low-income populations. ${ }^{16,17}$ The least expensive forms of food energy are foods in the fats category, grains, and other carbohydrates. ${ }^{18}$ Conversely, fruits and vegetables are the most expensive in terms of calories, whereas meat, poultry, and fish are the most expensive per serving. ${ }^{18}$ Individuals who are food insecure often rely on low-cost, energy-dense, but nutrient-poor foods to satisfy hunger. ${ }^{19}$

Empathy is increasingly viewed as an important attribute of health professionals. ${ }^{20-22}$ Empathy entails the moral imperative to be altruistic and the ability to experience another person's emotional state, accurately perceive 
and understand another's viewpoint, and communicate under-standing of the other's perspective. ${ }^{22-26}$ Empathetic interactions between health practitioners and clients can lead to strong rapport, increased trust, improved health outcomes, improved compliance, and positive patient satisfaction ratings. ${ }^{25,27}$ Empathy protects health care providers from burnout and improves well-being. ${ }^{28}$ In dietetics, empathy during consultations leads to higher patient satisfaction and greater agreement between patient and dietitian regarding what was discussed. ${ }^{29}$ Conversely, nonempathetic feelings when counseling obese patients have been associated with shorter counseling sessions, less effort, and a negative tone from the practitioner. ${ }^{30}$ Because empathy is a crucial skill that can be taught, training programs in the health professions strive to instill prosocial attitudes and the development of empathy in students. ${ }^{20,31}$ Current literature provided no examples of activities in dietetics education associated with increasing empathy.

To address the health risks associated with food insecurity and provide competent counsel, dietetics students and future health practitioners not only must understand the consequences of hunger and the stigma associated with both nutrition assistance and obesity; for the sake of better health outcomes, they must also have empathy when working with clients who struggle to afford nutritious diets. ${ }^{29,30}$

In an attempt to address this educational need, since 2005 dietetics students at Montana State University participated in a food insecurity experience (FIE) as part of their undergraduate curriculum. The FIE, which requires students to live on a limited food budget for 5 days, was intended to achieve the following learning outcomes: (1) students developed understanding about what it was like to be food insecure, (2) students developed strategies for maintaining a nutritious diet on a limited food budget, and (3) students gained empathy for individuals who were food insecure.

\section{Theoretical Foundation}

Transformative Learning Theory, which uses an experiential education approach, was the basis for the design of the FIE. ${ }^{32,33}$ Experiential education allows participants to learn by doing, whereas transformative learning entails reflection and openness to others' perspectives and ideas, providing the opportunity to construct a new or revised interpretation of the meaning of one's experiences to guide future action. Following the assumptions of the Transformative Learning Theory, the FIE simulated what was encountered by those dealing with food insecurity and required participants to reflect on their beliefs and attitudes toward individuals who were food insecure in light of their experience. This research used a mixed-methods approach to assess the impact of the FIE on the stated learning outcomes, including a quantitative survey and qualitative analysis of workbook journals.

\section{METHODS}

\section{The FIE}

The FIE required students to meet their food needs for 5 days with a total of $\$ 15$, eating only food for which they paid (free food and charity were not permitted) while also striving for a nutritionally balanced diet. Allowing approximately $\$ 3 / \mathrm{d}$ was based on typical Supplemental Nutrition Assistance Program (SNAP) allotments during the years of the study (the average monthly SNAP benefit per person in 2014 was $\$ 125.35$ or $\$ 4.17 / \mathrm{d}$, increased from $\$ 96.18$ in 2007 or $\$ 3.20 / d) .{ }^{34}$ Not allowing participants to use free food or charity during the 5 days was a condition intended to create a challenge in which participants had to consider how to budget a small amount of resources to include nutritious food and how to cope with the emotional, physical, and mental consequences of food insecurity. The abundance of free food on this college campus would have undermined the challenge of this relatively short-term experience.

Participants completed a 5-part workbook before, during, and after the experience (Figure 1). The workbook, which was divided into 5 parts, asked students to reflect on how they might feel during the experience and to consider what they would purchase with the limited food budget. In part 2 , students were asked to describe their shopping experience, list their purchases, and describe how they maximized the limited funds. Part 3 required students to describe their experience each day and to focus on how they felt physically, mentally, and emotionally. They were also asked to visit the county assistance office during the experience, to apply for food assistance, and to describe what that was like. Part 4 of the workbook required participants to complete a diet analysis using the nutrient analysis tool of their choice, and to assess how well their estimated needs were met. They were asked to reflect on the changes they made to comply with the conditions of the assignment, and how in retrospect they could have improved the quality of their diet on the limited budget. Finally, part 5 required students to visit and volunteer at the local food bank after the 5-day experience and to record observations. Students were also asked to reflect on the FIE as a whole, and consider what they had learned that might benefit them as future food and nutrition professionals whose clients may face food insecurity challenges.

In addition to the 5-day experience and workbook, participants were exposed to typical community nutrition classroom content, including lectures and activities related to poverty, hunger, and food assistance. Examples of class activities included comparing minimum wage earnings with poverty thresholds, discussing readings related to living in poverty, and exploring specific food assistance programs in small groups.

\section{Study Design and Sample}

A multiphase approach was used to assess the impact of the FIE compared with and combined with classroom content. A food insecurity survey was administered in years 1 and 2 to assess quantitative impacts of FIE on empathy. The researchers developed an original 5point Likert scale questionnaire to measure changes in empathy at different points in time. Items matching assignment objectives represented a broad range of attitudes toward food insecurity. The questionnaire was tested on a group of 10 nutrition graduate student volunteers for face validity and then was revised for clarity. The final 
Introduction:

The goal of this course activity is to see if you can meet your food needs on $\$ 3 /$ day for 5 days ( $\$ 15 / 5$ days).

The conditions of the assignment include the following:

- Strive for a nutritionally balanced diet.

- Do not accept any free food or charity over the 5 days.

- Only consume what you have purchased.

\section{Instructions:}

This assignment has 5 parts. Complete your answers to Part I before you begin the experience. Complete Part II after you have done your shopping. Complete Part III on a daily basis during the experience and Part IV when you have completed the experience. Part V has questions that should be completed after the experience. Use this workbook as your written log and then submit a typed version of your answers.

\section{Part I: Planning}

- Before you begin the experience, reflect on how do you think it might feel (physically, emotionally, and mentally) to be food insecure.

- Before you go shopping, what kinds of foods do you think you will buy with your $\$ 15$ ?

\section{Part II: Purchasing}

- Describe your shopping experience. Where did you shop, what did you buy, and how much did each item cost?

- What strategies did you use to maximize your allotted money?

- (Copy your receipts to turn in with your workbook)

\section{Part III: The Experience}

- For each day state what you ate, how you felt physically, mentally, and emotionally; and record your observations and insights.

- During the 5 days of the experience visit the county assistance office or other resource and obtain an application for food stamps. Examine and complete the application. Describe this experience. How difficult was it to obtain an application? How difficult was it to complete the application? Consider how the experience might have been different if you had poor reading or writing skills.

\section{Part IV: Analysis}

- For each day complete a diet analysis (attach printouts to this assignment sheet). What were your average intakes for the following macro and micronutrients? (State in amounts and percentages of recommended values): Calories, Fat, Carbohydrates, Protein, Fiber, Vitamin A, Vitamin C, Vitamin E, Calcium, Iron, Zinc, and Folate.

- Considering nutrients, food groups and other important food components, how well did you meet your nutrition needs?

- How could your diet have been improved (within your budget)?

- What did you eat that you normally do NOT eat?

- What foods do you normally eat that you have avoided?

- Did you have any difficulty complying with the conditions of the assignment?

- Could you continue to live on $\$ 3 /$ day? How would doing so change your life?

\section{Part V: Follow-Up}

- $\quad$ After the 5 day experience, visit and volunteer at the food bank for a few hours. Reflect on this experience. How did your 5 day experience affect your view of the emergency food supply and food bank clients?

- What are your overall conclusions about this experience? Describe what you learned, your observations and insights.

- What are the important things you learned during this experience that would benefit you as a food and nutrition professional?

Figure 1. Components of Food Insecurity Experience Workbook. The workbook is completed before during and after the food insecurity experience in 5 parts.

questionnaire contained 25 statements related to food insecurity with which respondents were asked to rate their level of agreement ( $5=$ strongly agree to 1 = strongly disagree) (Figure 2). Cronbach $\alpha$ was .80. Researchers collected qualitative data through participant workbooks during years $1-5$, in which year 1 was a pilot of the workbook (Table). Qualitative data used in analysis were derived from a revised workbook from years 2-5.
Although participating in this experience is a regular part of this community nutrition course, only responses from those students who provided informed consent were included in the analyses. This human subjects 
1. Food stamps only make people more dependent on government aid.

2. Food stamps provide plenty of money to help low income families meet their food needs.

3. If an individual or family cannot meet their food needs it is because they do not manage money well.

4. If a family cannot meet its food needs with the help of food stamps, it's because they waste money on junk food.

5. There are many individuals of families receiving food stamps who don't really qualify for aid.

6. The majority of Montana residents who are eligible for food stamps are already receiving them.

7. Not having enough money for the family can be a problem even when one or two parents have jobs.

8. Hunger is a growing problem for working individuals with lower paying jobs.

9. Individuals who are employed do not struggle with food shortages or hunger.

10. Individuals and families who struggle with meeting food needs probably have a history of unemployment.

11. It is important for food and nutrition professionals to understand the causes of hunger and food insecurity.

12. Food and nutrition professionals can make a contribution to strengthening food security in their communities.

13. Food and nutrition professionals really cannot do much about hunger.

14. The study of hunger is not really related to dietetics.

15. It is difficult to afford a balanced diet on a limited budget.

16. People who live on limited food budgets may have difficulty complying with prescribed diets because they cannot afford nutritious foods.

17. If individuals and families do not have enough food it is their own fault.

18. Individuals and families end up in a state of hunger because of a series of poor choices.

19. Individuals who experience hunger often do not comply with dietary instructions because they aren't motivated.

20. Those who experience hunger often lack the motivation to improve their situation on their own.

21. When grocery shopping, individuals who have difficulty affording enough food often purchase expensive, convenience foods instead of cheaper alternatives.

22. If someone is irritable, it could be because they are hungry.

23. Hunger can have significant impact on one's ability to learn.

24. One doesn't have to be well fed in order to perform well at work or school.

25. Not eating breakfast can make it hard to concentrate later.

* Likert-type scale questions ( 5 = strongly agree to $1=$ strongly disagree).

Figure 2. Food insecurity experience survey questions for dietetics students in community nutrition course

protocol was approved by the Institutional Review Board of Montana State University. Because community nutrition is a required course, the demographics of the study sample reflected dietetics program demographics: $97 \%$ female, 96\% Caucasian (2\% Asian and $2 \%$ Native American), and average age, 20 years.

In year 1, classroom content focused on poverty, hunger, and food assistance; then students participated in the FIE. In year 2, the FIE was repeated with 1 modification: the order of interventions was reversed such that the FIE preceded the class- room content. The crossover design was used to examine the impact of the FIE on survey responses separately and combined with the classroom content, and to assess which had the greatest impact alone. In years 3-5, the FIE experience always preceded the classroom content (Table).

\section{Quantitative Data and Statistical Analysis}

In year 1, participants completed the survey described previously before they were exposed to classroom content, again after being exposed to classroom content, and then once more after the FIE. In year 2, participants completed the survey before and after the FIE, and then once more after being exposed to classroom content. Data were coded and means were compared using paired $t$ tests from time I to time II, time II to time III, and time I to time III for years 1 and 2. Negative statements were reverse coded such that higher scores reflected greater empathy. Descriptive statistics and paired-sample $t$ tests for each time were used to test the effect of the FIE on overall empathy $(P<.05)$. All statistical tests were 
Table. Study Design and Sample of Food Insecurity Experience for Dietetics Students Participating in \$3/d Assignment in Community Nutrition Course

\begin{tabular}{|c|c|c|c|c|c|c|}
\hline Year & $\mathbf{n}$ & Time I & Intervention & Time II & Intervention & Time III \\
\hline 1 & 28 & Survey 1 & Classroom & Survey 2 & $\mathrm{FIE}$ & $\begin{array}{l}\text { Survey } 3 \\
\text { Online workbook } \\
\text { pilot }\end{array}$ \\
\hline 2 & 30 & $\begin{array}{l}\text { Survey } 1 \\
\text { Workbook part } 1\end{array}$ & $\begin{array}{l}\text { FIE } \\
\text { Workbook parts } 2 \text { and } 3\end{array}$ & $\begin{array}{l}\text { Survey } 2 \\
\text { Workbook parts } 4 \text { and } 5\end{array}$ & Classroom & Survey 3 \\
\hline 3 & 19 & Workbook part 1 & $\begin{array}{l}\text { FIE } \\
\text { Workbook parts } 2 \text { and } 3\end{array}$ & Workbook parts 4 and 5 & Classroom & $\mathrm{n} / \mathrm{a}$ \\
\hline 5 & 35 & Workbook part 1 & $\begin{array}{l}\text { FIE } \\
\text { Workbook parts } 2 \text { and } 3\end{array}$ & Workbook parts 4 and 5 & Classroom & $\mathrm{n} / \mathrm{a}$ \\
\hline
\end{tabular}

FIE indicates food insecurity experience; n/a, not available.

Note: Total $\mathrm{n}$ for FIE survey is 58 ; total $\mathrm{n}$ for workbook is 119.

conducted using SPSS (version 20.0, SPSS, Inc, Chicago, IL, 2011).

\section{Qualitative Data and Analysis}

The student workbook was piloted using an online format in year 1, which was completed entirely at the conclusion of the FIE. The revised workbook, which was used consistently in years 2-5 was a portable digital document that could be completed daily throughout the experience. Members of the research team manually coded a total of 119 workbooks using predetermined categories, which corresponded directly to workbook sections (Figure 1). One researcher coded years 2 and 4, another years 3 and 5, and the third all 4 years, to ensure consistency. Coders had regular meetings to compare and discuss results. Disagreements were rare; in each case the third coder provided assistance in coming to consensus. The aim of coding varied for each category (workbook section). For most categories, themes and most common responses were identified to assess how participants responded to the exercise in general. However, when participants reported strategies, coders aimed to capture the whole diversity of responses rather than just common themes.

\section{RESULTS}

Food Insecurity Experience Survey Results

The FIE survey indicated that both classroom content and experiential ex- ercises were important for enhancing empathy about hunger and food insecurity among food and nutrition students. The order of interventions did not seem to affect the end result. Both experimental groups showed significant $(P<.05)$ increases in total empathy survey scores (mean \pm SD) for year 1 from time I $(3.90 \pm 0.86)$ to time II (4.08 \pm .83$)$ and from time I to time III $(4.14 \pm 0.75)$, and for year 2 from time I $(3.89 \pm 0.91)$ to time II (3.97 \pm 0.88$)$ and from time I to Time III $(4.00 \pm 0.90)$. Additional increases from time II to time III were not significant but may have demonstrated that the second component of the intervention, whether classroom or experiential, also had importance overall.

\section{Qualitative Results}

Participant strategies for meeting food needs on a limited budget. Generally, participants chose 1 of 2 overall strategies: acquiring a larger quantity of food at the expense of nutrition and quality (inexpensive processed boxed meals) or acquiring more nutritious whole foods, often at the expense of quantity (fresh produce) or time for food preparation (dry beans and rice) (Figure 3). Money-saving strategies included creating a shopping list, bringing a calculator to keep a running tally of expenses, surveying the entire store for sales before making selections, comparing prices of bulk items with individually packaged items, choosing foods that could be incorporated into more than 1 meal, and choosing smaller-sized items that could be consumed within 5 days with no portion remaining. Participants used a discount produce rack at 1 store to afford fresh fruits and vegetables. Most participants deviated from their normal behaviors while food shopping because the primary objective was to spend very little money. For example, they eliminated foods perceived as luxury items, incorporated less expensive replacements for commonly eaten foods, consumed smaller amounts of usual food items, or ate foods that were not typical (Figure 3).

Participants cited strategies for living on a limited food budget in the longer term: more time for menu planning, shopping, and preparing foods; developing more creative cooking skills; reducing food waste; limiting treats; and paying more attention to grocery store sales and coupons. Another common strategy was becoming more self-sufficient by producing or processing some of their own foods through gardening and preservation. Many stated they would seek assistance through food banks, SNAP, the Special Supplemental Nutrition Program for Women, Infants and Children, or other sources of free or low-cost meals, while also seeking higher wage employment.

Consequences of food insecurity: physical, mental, and emotional. As participants worked through the experience, the way they described their physical, mental, and emotional states became more extreme. At the 


\begin{tabular}{|c|c|}
\hline Foods Participants Planned to Purchase & Foods Participants Actually Purchased \\
\hline $\begin{array}{l}\text { Apples, bananas, carrots } \\
\text { Canned or frozen vegetables } \\
\text { Bread, oats, rice, pasta and cereals } \\
\text { Eggs, } \\
\text { Beans and peanut butter } \\
\text { Milk and yogurt }\end{array}$ & $\begin{array}{l}\text { Boxed macaroni and cheese } \\
\text { Instant rice meals } \\
\text { Ramen noodles } \\
\text { Frozen and canned fruits and vegetables } \\
\text { Store brand or generic items }\end{array}$ \\
\hline Luxury Foods Avoided by Participants & $\begin{array}{l}\text { Foods Identified as Staples for Long-term Food } \\
\text { Insecurity }\end{array}$ \\
\hline $\begin{array}{l}\text { Butter, yogurt, cheese } \\
\text { Meats and other animal products } \\
\text { Sweets/candy, chocolate, ice-cream } \\
\text { Healthy fats } \\
\text { Coffee, tea, soda, alcohol } \\
\text { Seasonings } \\
\text { Certified organic options } \\
\text { Locally grown foods }\end{array}$ & $\begin{array}{l}\text { Rice, oatmeal, cereal, Ramen noodles } \\
\text { Frozen or canned fruits and vegetables } \\
\text { Eggs, peanut butter, beans, lentils } \\
\text { Milk } \\
\text { Chicken }\end{array}$ \\
\hline
\end{tabular}

Figure 3. Food and nutrition students developed strategies for long-term food insecurity during a food insecurity experience: foods they purchased and avoided.

beginning, participants most commonly described their physical state as hungry and tired. Whereas some participants felt relatively normal early on, others felt frustrated and tempted by cravings, and reported headaches. Some reported feeling emotionally stressed and insecure:

\section{... food insecurity is more than just hunger. It is a mental state of worry. I was constantly thinking about food, and what my next meal was going to be. I noticed as the days went on I became more and more easily irritated and seemed stressed out all the time.}

By the third day of the experience, participants felt mentally distracted, lacked focus, felt less motivated, had difficulty concentrating, and experienced boredom with repetitive and limited food choices. Participants described their emotions with words such as cranky, annoyed, grumpy, irritable, and worried. By the fourth day, they reported tiredness more than hunger: "Being food insecure is exhausting."

Compliance with conditions of the experience. Most participants (83\%) reported difficulty complying with all the conditions of the experience, and $32 \%$ reported that they failed to comply at least once during the 5 days. For example, some students could not resist joining in a social activity involving food with friends, others enjoyed a dessert during the week, and some felt that they had to have coffee to stay awake at least once during the FIE.

Diet quality. Based on participant calculations, using the nutrient analysis program of their choice, the majority of participants did not meet their calculated estimated energy needs. On average, participants consumed $60 \%$ of their required calories as determined by a nutrient analysis of the 5day experience. Nonetheless, on average, participants consumed 108\% of their protein requirements. These results reflect the importance they placed on protein in the diet.

At the conclusion of the experience, participants identified a variety of strategies for improving nutrient intake on a limited budget. Buying whole foods in bulk at a lower price was a common recommendation, as was purchasing more canned foods vs fresh and using more coupons. Researching the nutrient content of foods while planning a diet was seen as a strategy to improve the intake of particular nutrients, such as vitamins. Many concluded that they should have purchased more fresh produce rather than meat because of both cost and specific nutrients missing from their diet, as revealed by a nutrient analysis. Increasing reliance on fortified cereals and peanut butter was another perceived strategy to improve diet quality. Consuming fortified cereals would have affected the nutrient intake analysis, although they were commonly more expensive than bulk whole grains.

Variety, social eating, and calorie conservation. In recording insights and observations during the FIE, participants learned the importance of dietary variety, flavors, and food preparation skills. Participants also struggled with allocating time to prepare the whole foods they had purchased and arranging access to those foods during the day.

Another important insight common among participants was a new recognition of the importance of sharing meals with others and being able to express one's values with food choices. Participants reported struggling with watching others eat and viewing food advertisements. Some expressed unhappiness, a hesitation to 
talk or interact with others, and purposeful avoidance of places where there would be food and food smells, such as the student union or other eateries: "I did not want to talk to anyone or anyone to talk to me." They became increasingly frustrated by having to turn down invitations to eat socially with friends: "I just want to be normal; I just want to stop thinking about food. I feel so different from everyone else." They experienced tension with friends and family members, and reported being moody and stressed. They did not look forward to eating. Some participants expressed disappointment that they were not able to consume particular foods that were organically or sustainably produced, because the costs of those foods were prohibitive on such a limited budget.

In coping with a limited food budget, participants focused on conserving calories by rationing food and limiting exercise. In retrospect, rationing was less necessary than thought, because most noted they had food left over at the end. By the second day, a predominant realization among participants was the impossibility of running or performing other calorically expensive exercise during the remainder of the 5 days. Experiencing a limited capacity to exercise was difficult for otherwise active college students.

Additional insights among participants conveyed guilt, empathy, compassion, and raised consciousness:

I keep thinking of what my 'celebration' dinner will be for making it through this project and I realize that it was only 5 days but it was a very difficult period of time. Then I feel guilty because there are people who live like this every day who are not able to go out and have a celebration dinner for all the suffering that they experience and I have suddenly lost my desire to go out.

I thought I would be proud of what I have done as though I contributed something to society, but that is not the case. I have learned not to take for granted my ability to eat healthy and generously.

Some noted that living on a limited budget would be even more difficult if one had dependents, and recognized that a food-insecure family might also be challenged to pay rent or heating bills, afford clothes, or purchase medicines for children. Participants reflected on how demeaning it felt to be food insecure. Many felt joyful that they did not face those burdens in their daily lives: "I feel like a prisoner being released that does not deserve the release. I feel like a traitor. I am going back to my old way of eating, but other people cannot afford to follow."

Seeking public food assistance. Participants had fairly consistent reactions to visiting the county assistance office as required, to conclude the FIE. Many printed a food stamp/SNAP application online because they were too embarrassed to go into the office:

I was conscious of how I do not look like the 'typical' individual in need of food stamps, which in turn brought my awareness to my own stereotypes and the complexity of the evaluation process.

Those who entered the assistance office reported that they felt awkward, watched, and judged.

The vast majority of participants reported that they found the application difficult to complete. Questions were hard to understand, even for college students. One student stated, "While I was there, there was a man who had some difficulty and had to ask the clerk a lot of questions and start over a couple of times." Others reported that filling out the application itself was intimidating because it was about 12 pages long, as well as humiliating because of the probing nature of many of the questions and the warnings and penalties inserted throughout.

Seeking emergency food. Participants were required to visit the local food bank after completing the FIE, which further broadened their perspectives:

\begin{abstract}
After completing the 5-day experience, it became very obvious to me that food banks and emergency food supplies are very important to many people who do not have the means to be able to afford food for themselves and/or their families.
\end{abstract}

Another common response to visiting the food bank was awareness about the overall lack of choice among the foods offered. They noticed that although food seemed to be plentiful at the food bank, the options were not particularly healthful and fresh produce and dairy products were lacking. Participants observed how wasteful their typical consumption patterns were and expressed some appreciation for their own economic status. They demonstrated empathy toward food bank clients, citing a better understanding of how it feels to be food insecure.

The FIE and professional development. At the conclusion of the assignment, participants reflected on how the FIE prepared them to be food and nutrition professionals, generally reporting greater awareness of the need to be understanding, compassionate, caring, sensitive, patient, and empathetic toward individuals who are food insecure: "Before this experience, I don't know if I could have given proper advice to those who do not have enough money for food." Some participants had not really been aware of the foodinsecure population before the experience. Some thought that additional nutrition information and education for those living on a limited budget would be helpful. Others stated that it was helpful to understand more about the impact of food insecurity and hunger on one's physical, mental, and emotional state: "It is an experience that, unless you actually go through it, there's no way to imagine what it's like." Participants who stated they were interested in nutrition counseling as a career shared the recognition that they would need to become more competent in developing creative, nutritious meal plans for every kind of budget: "I also learned that some recommendations that I would previously have given would be unrealistic for someone on a limited budget."

Participants thought it was helpful to experience what clients would experience in seeking food assistance and visiting the food bank. Participants also recognized the links among poverty, poor nutrition, and disease and the difficulty of following a special diet on a limited income. Some participants also wrote about the 
need to work on community and social issues to address root causes rather than developing generalized programs that address only symptoms. Participants expressed that they had a greater understanding of what community nutrition work entails, and the influence they would like to have on the system:

I also believe that experiencing some form of food insecurity is vital in the ability to empathize with potential clients and also making movements for change.

\section{DISCUSSION}

This research showed that experiential and transformational learning can take place in a 5-day FIE that is incorporated into a typical university-level community nutrition course. Participant insights indicated improved understanding that food security is an important part of having a healthful, enjoyable, and varied diet; being physically active, mentally attentive, and emotionally stable; and having positive social relations with friends and family. Participants became more aware of money spent on luxury foods, the amount of food they typically wasted, and the time required to prepare whole nutritious meals. Most meaningfully, participants realized the importance of understanding food insecurity for becoming competent food and nutrition professionals.

Researchers in other health professions disciplines attempted to measure empathy in students. ${ }^{35,36}$ Researchers deemed empathy levels among occupational therapy students to be good, but no specific training was provided to increase empathy and levels did not change over the course of the academic program year. $^{36}$ Increasing empathy levels may in fact depend on deliberate use of course activities in which students engage in a transformative learning experience, as described in the current study.

Researchers in nursing education exposed a cohort of nursing students to a training course in which they attended seminars and laboratories in small groups to learn and develop communicative and empathic abilities. $^{25}$ The training course was effective, especially for women.
Researchers concluded that empathy could indeed be taught, and that empathy-building experiences should be included in the traditional nursing curriculum. The results of the current study also indicated that empathy could be taught, and suggested that empathy-building experiences should be included in the dietetics curriculum.

A transformational learning intervention was tested in a dental education study. Audio recordings of patients' voices were incorporated into lectures, followed by classroom discussions and reflective journaling. Resulting student perceptions indicated that this teaching enhancement raised their awareness of the importance of empathy. ${ }^{37}$ In the current study, completing the FIE allowed dietetics students figuratively to hear the voices of their future clients who were food insecure; similarly, their empathy increased.

Pharmacy students participated in a simulation in which they kept a nutrition journal and shopped as if they were patients with diabetes. The results of this educational activity were increased confidence, increased empathy, greater appreciation for the difficulties patients had with healthy eating, and increased empathy toward patients with diverse cultural and socioeconomic backgrounds. ${ }^{38}$ These results were consistent with the results of the current study and the impact of the FIE on dietetics students.

Medical students suggested that their empathy increased when their educators modeled empathy and assisted students in processing and reflecting on real or simulated clinical sessions. ${ }^{39}$ Although not included in data analysis, dietetics students who participated in the FIE also participated in oral debriefing of their experience with their classmates after completing and submitting their workbooks. This class discussion was likely an important way to ensure participants had an opportunity to reflect further on what they learned, listen to one another, and consider the larger implications of food insecurity. In the case of the FIE, the transformational learning went beyond developing empathy for people who were food insecure. Building this awareness also resulted in motivation to address the root causes of hunger in society and to change food systems in ways that create improved food security for both individuals and communities.

The conditions of the FIE created some limitations that should be noted. Not allowing participants to use free food or charity during the 5 days created an artificial challenge that may not be realistic, because incorporating free food can be a viable strategy for coping with food insecurity. Five days is a relatively short period of time to experience food insecurity, and the abundance of free food on this university campus would have ensured that participants experienced no hunger. A longer period would have provided the opportunity for a more realistic experience. About a third of participants admitted to breaking the established rules of the FIE at least once. They had faced choices and trade-offs that foodinsecure individuals might face. However, if this were not a simulation, noncompliance may have had more serious consequences, ie, less money to pay for rent, heating, medicines, or clothing. Overall, what the participants experienced and reported in their daily reflections were expected consequences of inadequate caloric intake, which were consistent with reports in current literature. ${ }^{2-11}$

\section{IMPLICATIONS FOR RESEARCH AND PRACTICE}

This experience and other opportunities for transformational learning could be considered for inclusion in university-level community nutrition courses and for professionals at any stage of development; indeed, the authors all participated in this transformative exercise at least once. The conditions of the experience could be modified to improve effectiveness, depending on the audience, circumstances, and specific learning outcomes desired. For example, the dollar amount allowed for food expenses could be increased to simulate current SNAP allotments. The experience could be extended to encourage the development of longer-term strategies and coping, while allowing free food and charity to be used. Other challenges could be added, such as 
not allowing the use of a personal vehicle to shop for food, or allowing food purchases only from the location closest to one's residence or from a store accessible by public transportation. Future research might also address the long-term impact of the activity, or how completing a food insecurity challenge can affect experienced practitioners in addition to practitioners in supervised practice.

\section{REFERENCES}

1. US Department of Agriculture Economic Research Service. Food security in the U.S. http://www.ers.usda.gov/ topics/food-nutrition-assistance/foodsecurity-in-the-us/key-statistics-graphics. aspx\#foodsecure. Accessed October 14, 2016.

2. Nord M. What have we learned from 2 decades of research on household food security? Pub Health Nutr. 2014;17:2-4.

3. Bernal J, Frongillo EA, Herrera H, Rivera J. Children live, feel, and respond to experiences of food insecurity that compromise their development and weight status in peri-urban Venezuela. J Nutr. 2012;142:1343-1349.

4. Weinreb L, Wehler C, Perloff J, et al. Hunger: its impact on children's health and mental health. Pediatrics. 2002;110:e41.

5. Roseboom TJ, Painter RC, van Abeelen AFM, Veenendaal MVE, de Rooij SR. Hunger in the womb: what are the consequences? Lessons from the Dutch famine. Maturitas. 2011;70:141-145.

6. Chilton M, Booth S. Hunger of body and hunger of the mind: African American women's perceptions of food insecurity, health and violence. J Nutr Educ Behav. 2007;39:116-125.

7. Heflin CM, Siefert K, Williams DR. Food insufficiency and women's mental health: findings from a 3-year panel of welfare recipients. Soc Sci Med. 2005; 61:1971-1982.

8. Siefert K, Heflin CM, Corcoran ME, Williams DR. Food insufficiency and the physical and mental health of lowincome women. Women \& Health. 2001;32:159-177.

9. McLaughlin KA, Green JG, Alegria M, et al. Food insecurity and mental disorders in a national sample of US adolescents. J Am Acad Child Adolesc Psychiatry. 2012;51:1293-1303.
10. Kirkpatrick SI, McIntyre L, Melissa L, Potestio ML. Child hunger and longterm adverse consequences for health. Arch Pediatr Adolesc Med. 2010;164: 754-762.

11. Alaimo K, Olson CM, Frongillo EA. Food insufficiency and American school-aged children's cognitive, academic, and psychosocial development. Am Acad Pediatrics. 2001;108:44-53.

12. Pan L, Sherry B, Njai R, Blanck HM. Food insecurity is associated with obesity among US adults in 12 states. J Acad Nutr Diet. 2012;1129:1403-1409.

13. Larson N, Story M. Food insecurity and risk for obesity among children and families: is there a relationship? http://www.banpac.org/pdfs/resources_ food_security/2010/rwj_obesity_food_ insecurity_12_2_10.pdf. Accessed November 28, 2016.

14. Eisenmann JC, Gunderson C, Lohman BJ, Garasky S, Stewart SD. Is food insecurity related to overweight and obesity in children and adolescents? A summary of studies, 1995-2009. Obes Rev. 2011;12:e73-e83.

15. Townsend M, Melgar-Quinonez $H$ Hunger, food insecurity, and child obesity. US Dept of Agriculture Economic Research Service; 2003. Food Assistance and Nutrition Research Report No. 38.

16. Selligman HK, Laraia BA, Kushel MB Food insecurity is associated with chronic disease among low-income NHANES participants. J Nutr. 2010; 140:304-310.

17. Selligman HK, Bindmann AB, Vittinghoff E, Kanaya AM, Kushel MB. Food insecurity is associated with diabetes mellitus: results from the National Health Examination and Nutrition Examination Survey (NHANES) 1999-2002. J Gen Intern Med. 2007;22:1018-1023.

18. Drewnowski A. The cost of US foods as related to their nutritive value. $A m$ J Clin Nutr. 2010;92:1181-1188.

19. Nord M, Coleman-Jensen A, Andrews M, Carlson S. Household food security in the United States in 2009. US Dept of Agriculture Economic Research Service; 2010. Report No. ERR108.

20. Burks DJ, Kobus AM. The legacy of altruism in health care: the promotion of empathy, prosociality and humanism. Med Educ. 2012;46:317-325.

21. Graber DR, Mitcham MD, CokerBolt P, et al. The caring professionals program: educational approaches that integrate caring attitudes and empathic behaviors into health professions education. J Allied Health. 2012;41:90-96.

22. Holm U. Empathy and professional attitude in social workers and non-trained aides. Int J Soc Welfare. 2002;11:66-75.

23. Morse J, Anderson G, Botter J, Yonge O, O'Brien B, Solberg S. Exploring empathy: a conceptual fit for nursing practice? J Nurs Scholarship. 1992;24:273-280.

24. Brown T, Boyle M, Williams B, et al. Predictors of empathy in health science participants. J Allied Health. 2011;40: 143-149.

25. Nash DA. Ethics, empathy, and the education of dentists. J Dental Educ. 2010; 74:567-578.

26. Halpern J. What is clinical empathy? J Gen Intern Med. 2003;18:670-674.

27. Lelorain S, Bredart A, Dolbeault S, Sultan S. A systematic review of the associations between empathy measures and patient outcomes in cancer care. Psychooncology. 2012;21:1255-1264.

28. Kliszcs J, Nowicka-Sauer K, Trzeciak B, Nowak P, Sadowska A. Empathy in healthcare providers - validation study of the Polish version of the Jefferson Scale of Empathy. Adv Med Sci. 2006;51:221-225.

29. Goodchild CE, Skinner TC, Parkin T. The value of empathy in dietetic consultations: a pilot study to investigate its effect on satisfaction, autonomy, and agreement. J Hum Nutr Dietet. 2005;18:181-185.

30. Stone O, Werner P. Israeli dietitians professional stigma attached to obese patients. Qual Health Res. 2012;22: 768-776.

31. Cunico L, Sartori R, Marognolli O, Meneghini AM. Developing empathy in nursing students: a cohort longitudinal study. J Clin Nurs. 2012;21: 2016-2025.

32. Merizow J. Transformative Dimensions of Adult Learning. San Francisco, CA: Jossey-Bass; 1991:22-31.

33. Kolb D. Experiential Learning: Experience as the Source of Learning and Development. Englewood Cliffs, NJ: Prentice Hall; 1984:21.

34. Supplemental Nutrition Assistance Program Participation and costs. US Department of Agriculture, Food and Nutrition Service. http://www.fns. usda.gov/pd/supplemental-nutritionassistance-program-snap. Accessed November 28, 2016.

35. Williams B, Boyle M, Earl T. Measurement of empathy levels in 
undergraduate paramedic students. Preshosp Disaster Med. 2013;28: 145-149.

36. Brown T, Williams B, Boyle M, et al. Levels of empathy in undergraduate occupational therapy students. Occup Ther Int. 2010;17:135-141.
37. Schwartz B, Bohay R. Can patients help teach professionalism and empathy to dental students? Adding patient videos to a lecture course. I Dental Educ. 2012;76:174-184.

38. Trujillo JM, Hardy Y. A nutrition journal and diabetes shopping experience to improve pharmacy students' empathy and cultural competence. Am J Pharm Educ. 2009;73:1-10.

39. Winseman J, Malik A, Morrison J, Balkoski V. Students' views on factors affecting empathy in medical education. Acad Psychiatry. 2009;33:484-491. 